\title{
Identidades Sexuais Não-hegemônicas: Processos Identitários e Estratégias para Lidar com o Preconceito ${ }^{1}$
}

\author{
Ana Flávia do Amaral Madureira \\ Angela Maria Cristina Uchôa de Abreu Branco \\ Universidade de Brasília
}

\begin{abstract}
RESUMO - A partir da perspectiva sociocultural construtivista, o artigo tem como objetivo analisar a construção das identidades sexuais não-hegemônicas em jovens adultos na cidade de Brasília, com base em uma pesquisa qualitativa que partiu do questionamento amplo: como sujeitos concretos dão sentido às suas vivências homoeróticas? Participaram da pesquisa seis homens e quatro mulheres de classe média de Brasília que se reconhecem como pessoas que apresentam uma orientação sexual distinta da heterossexualidade. O estudo indicou a importância das estratégias pessoais e coletivas utilizadas no cotidiano para lidar com o preconceito e a discriminação em relação às identidades sexuais não-hegemônicas. Tais estratégias são constitutivas da forma como os(as) participantes vivenciam as suas experiências homoeróticas, bem como se posicionam em suas relações sociais e consigo mesmos(as).
\end{abstract}

Palavras-chave: gênero; sexualidade; homossexualidade; identidades sexuais; preconceito.

\section{Non-hegemonic Sexual Identities: Identity Processes and Coping Strategies Concerning Prejudice}

\begin{abstract}
As from a constructivist sociocultural perspective, the present article aims at analyzing the construction of non-hegemonic sexual identities in young adults living in the city of Brasilia, based on a qualitative research starting from a broad questioning: how do individuals give meaning to their homoerotic experiences? Six middle-class men and four women living in Brasilia, who see themselves as non-heterosexually oriented, participated in the research. The results indicate the importance of collective and personal strategies employed in daily life by the individuals to cope with prejudice and discrimination related to non-hegemonic sexual identities. Such strategies are constituent of the way the participants live with their homoerotic experiences, as well as with their social relations, and with themselves.
\end{abstract}

Key words: gender; sexuality; homosexuality, sexual identities; prejudice.

“(...) Nada mudará na sociedade se os mecanismos de poder que funcionam fora, abaixo, ao lado dos aparelhos do Estado a um nível muito mais elementar, quotidiano, não forem modificados" (Foucault, 1996, p. 149-150).

A partir da perspectiva sociocultural construtivista, o presente artigo tem como objetivo analisar a construção das identidades sexuais não-hegemônicas em jovens adultos na cidade de Brasília, com base em uma pesquisa qualitativa que partiu do questionamento amplo: como sujeitos concretos dão sentido às suas vivências homoeróticas?

Neste artigo, destacamos as relações entre os processos identitários e a construção de estratégias para lidar com o preconceito e a discriminação no que tange às identidades

1 A pesquisa apresentada neste artigo corresponde à Dissertação de Mestrado da primeira autora, sob a orientação da segunda, intitulada A construção das identidades sexuais não-hegemônicas: gênero, linguagem e constituição da subjetividade. Dissertação de Mestrado defendida no Instituto de Psicologia da Universidade de Brasília em dezembro de 2000. Apoio: Conselho Nacional de Desenvolvimento Científico e Tecnológico - CNPq.

2 Endereço: SHCGN 716, Bloco G, Apto. 312, Brasília, DF, Brasil 70770737.E-mail: afam2001@terra.com.br sexuais não-hegemônicas, com base em um 'olhar' crítico ao modelo biomédico tradicional, marcado por uma leitura essencialista e biologizante sobre a sexualidade. Para tanto, foi de fundamental importância o estabelecimento de pontes interdisciplinares que viabilizaram transcender a nossa formação acadêmica, situada no contexto da ciência psicológica. Ir além dos conhecimentos produzidos pela psicologia é uma necessidade, considerando o caráter eminentemente interdisciplinar dos estudos de gênero e sexualidade.

Inicialmente apresentaremos algumas considerações sobre a nossa perspectiva teórica e sobre os processos identitários, com destaque para as identidades de gênero e as identidades sexuais.

\section{A perspectiva sociocultural construtivista}

$\mathrm{Na}$ atividade de pesquisa, sempre partimos de um referencial teórico que orienta o nosso "olhar" e a nossa ação, enquanto pesquisadores(as). Mesmo quando dialogamos com outras abordagens teóricas, é fundamental não perdermos de vista o nosso ponto de partida teórico. Ao realizarmos um percurso interpretativo sobre determinada temática, encontraremos uma multiplicidade de autores(as) e de abordagens teóricas provenientes de diversas áreas do conhecimento e 
para não nos perdermos nesse percurso é essencial explicitar não apenas os nossos objetivos (aonde desejamos chegar), mas também as nossas bases teórico-epistemológicas. De forma mais específica, o que caracteriza a perspectiva sociocultural construtivista?

Apesar da consciência das dificuldades inerentes a qualquer definição, definimos de forma didática a perspectiva sociocultural construtivista como uma perspectiva teórica, inserida no contexto das correntes sociogenéticas, que busca, por meio da síntese criativa das contribuições da Psicologia Histórico-Cultural de Vygotsky e colaboradores e do construtivismo piagetiano (a partir da ênfase no papel ativo e intencional do sujeito no seu desenvolvimento), compreender o desenvolvimento humano como fenômeno dinâmico e complexo (Madureira \& Branco, 2005a). Cabe destacar que, para esta perspectiva teórica, o conceito de cultura ocupa um lugar de destaque. A cultura não é concebida apenas como uma variável a ser considerada, uma variável "externa" que influencia as ações, pensamentos e emoções individuais. A cultura não é uma variável, mas sim o meio em que vivem e se desenvolvem os seres humanos (Cole, 1992). Portanto, a cultura não apresenta uma influência apenas indireta, a cultura $^{3}$ constitui o próprio desenvolvimento humano (Bruner, 1990/1997; Rogoff, 2003).

Para Lev Semenovich Vygotsky (1978/1991), autor importante da perspectiva teórica que adotamos, a relação entre o ser humano e o ambiente não é uma relação direta, mas sim mediada semioticamente. Nesse sentido, podemos definir a semiótica como o campo de conhecimento que estuda os signos que correspondem, em última instância, a "elementos que representam ou expressam outros objetos, eventos, situações (...)" (Oliveira, 1993, p. 30). Em outras palavras, os signos tornam presentes objetos, eventos ou situações que estão ausentes no aqui e agora.

As operações com signos ampliam, de forma considerável, as possibilidades de ação humana, tanto no plano interpsicológico como no plano intrapsicológico, na medida em que tornam a comunicação humana mais precisa, possibilitando, por exemplo, o planejamento coletivo da ação, bem como transformando, de forma qualitativa, o funcionamento psicológico humano (Vygotsky, 1978/1991). Para a psicologia histórico-cultural de Vygotsky e colaboradores, a linguagem, enquanto sistema de mediação semiótica, cumpre um papel fundamental na consciência humana.

$\mathrm{O}$ pensamento e a linguagem, que refletem a realidade de uma forma diferente daquela da percepção, são a chave para a compreensão da natureza da consciência humana. As palavras desempenham um papel central não só no desenvolvimento do pensamento, mas também na evolução histórica da consciência como um todo. Uma palavra é um microcosmo da consciência humana. (Vygotsky, 1962/1993)

De forma coerente com o referencial teórico adotado (Madureira \& Branco, 2005a; Valsiner, 1994, 1998) não poderíamos adotar uma ontologia apriorística sobre o sujeito e a realidade, na medida em que a mesma implica em uma

3 Para uma discussão mais aprofundada sobre o conceito de cultura na perspectiva sociocultural construtivista, consultar: Valsiner (1989, 1994, 1997, 1998) e Madureira e Branco (2005a). compreensão essencialista, descontextualizada. Defendemos, portanto, uma ontologia histórica (González Rey, 1997), destacando que tanto o sujeito como os fenômenos sociais estão sempre inscritos em uma temporalidade que não pode ser simplesmente "suspensa" sob o pretexto de buscarmos a sua "essência atemporal". Não há, portanto, essências supra-históricas, mas sim a constante tensão dialética entre organização e processo, estabilidade e transformação, continuidade e ruptura. Tensão que marca a constituição do sujeito $^{4}$ e o próprio desenvolvimento cultural.

É a partir da inserção nesse quadro teórico-conceitual que podemos afirmar a importância do estudo dos significados culturais, que mediam tanto a relação das pessoas concretas com o mundo social em que estão inseridas quanto a relação que estabelecem consigo mesmas. $\mathrm{O}$ estudo dos significados culturais (Bruner, 1990/1997) é de grande relevância quando focalizamos os processos identitários relacionados à construção das múltiplas identidades sociais e, de forma mais específica, das identidades sexuais e das identidades de gênero.

\section{Processos identitários: a construção das identidades sexuais e das identidades de gênero}

O conceito de identidade social está relacionado às posições que o sujeito assume na complexa rede de significações culturais, ao sentimento de pertencimento a um determinado grupo social de referência (Hall, 1992/1998; Louro, 1998, 1999; Parker, 1999). Cabe destacar que os processos identitários funcionam como coordenadas culturais no processo de constituição da subjetividade, além de posicionarem os sujeitos concretos em suas relações com os diversos grupos sociais existentes nos contextos culturais em que estão inseridos. No contexto deste artigo focalizaremos, a partir do estudo dos processos identitários, as identidades de gênero (as múltiplas formas de tornar-se homem ou mulher) e as identidades sexuais (as múltiplas formas como são subjetivadas as orientações sexuais).

É interessante notar que, para o senso comum, é perfeitamente compreensível que uma pessoa mude a sua identidade profissional, ou mesmo a sua identidade de classe social. Entretanto, a sua identidade de gênero e a sua identidade sexual são consideradas como essências imutáveis, como dados apriorísticos que definem o que há de mais fundamental no sujeito (Louro, 1999). Nesse sentido,

Quando uma figura de destaque assume, publicamente, sua condição de gay ou de lésbica (...) é freqüentemente vista como protagonizando uma fraude; como se esse sujeito tivesse induzido os demais a um erro, a um engano. A admissão de uma nova identidade sexual ou de uma nova identidade de gênero é considerada uma alteração essencial, uma alteração que atinge a "essência” do sujeito. (Louro, 1999, p. 12-13)

4 Para uma discussão mais aprofundada sobre a noção de sujeito na ciência psicológica, bem como sobre o papel da linguagem, enquanto sistema de mediação semiótica, na constituição da subjetividade, consultar: Madureira e Branco (2005b). 
As identidades de gênero e as identidades sexuais, tradicionalmente, são consideradas como entidades estáticas intrapsíquicas. Mais do que isso, são consideradas como o que, realmente, define a "natureza essencial" de uma pessoa. Nesse sentido, coerente com tal lógica essencialista, são consideradas como marcas inscritas nos corpos, não apresentando nenhuma relação com os contextos socioculturais em que o sujeito se insere. Não é de se estranhar, portanto, a obsessão de inúmeros cientistas e do público em geral em encontrar o gene (a "marca genética") responsável pela homossexualidade. Curiosamente, tal obsessão está circunscrita às orientações sexuais distintas da norma heterossexual, como se apenas o que é considerado socialmente "desviante" merecesse explicações.

No século XX, principalmente em suas últimas décadas, inúmeras mudanças, contudo, vieram a perturbar esse cenário de suposta tranqüilidade e simplicidade na compreensão da relação entre sujeito, sexualidade e gênero, como, por exemplo, a entrada da mulher no mercado de trabalho, novas tecnologias reprodutivas, o movimento feminista, os movimentos de gays e lésbicas, novas estruturas familiares, etc. O que era considerado exclusivamente como objeto de estudo das ciências biomédicas, diante dessa multiplicidade de mudanças relativas à sexualidade e ao gênero, tornou-se, cada vez mais, objeto de interesse das ciências humanas e sociais nas últimas décadas (Parker \& Barbosa, 1996). Neste contexto, um dos autores que têm inspirado inúmeros trabalhos nas ciências sociais sobre a temática relacionada à sexualidade é o filósofo francês Michel Foucault (19261984), autor de grande impacto nas formulações atuais das ciências sociais (Hall, 1992/1998; Heilborn, 1996; Louro, 1998, 1999; Weeks, 1999).

Considerando as limitações de espaço de um artigo abordaremos algumas questões levantadas por Foucault em suas últimas obras (publicadas na década de 1970 e 1980), referentes à genealogia do poder e à hermenêutica do sujeito. Tais obras influenciaram não só os estudos de diversos cientistas sociais, mas também movimentos organizados da sociedade civil, como o movimento feminista atual e o movimento de gays e lésbicas.

Segundo Foucault (1976/1997), a partir do final do século XVII, o sexo não é "convidado a se calar", ao contrário, o sexo é colocado em discurso, é incitado a se manifestar. Não é de se estranhar, portanto, que no século XIX seja sistematizada uma scientia sexualis, voltada para a produção de verdades sobre o sexo (antes do século XIX nem mesmo existia o termo sexualidade).

A emergência de uma scientia sexualis está intrinsecamente relacionada ao surgimento da noção de população, no final do século XVIII na Europa, como um problema político, econômico, demográfico e sanitário (Foucault, 1976/1997). Em outros termos, o surgimento da população, enquanto problemática multifacetada, criou a necessidade de um investimento disciplinar não apenas sobre o corpo individual, mas também sobre o corpo social. Tornou-se necessário um controle sobre a vida, a elaboração de uma biopolítica que garantisse, duplamente, a produção de corpos dóceis e saudáveis, individualmente, e a produção de uma população também dócil e saudável (Foucault, 1976/1997).
A sexualidade, portanto, constituiu-se em um dispositivo histórico de poder nas sociedades ocidentais modernas. Mais do que uma questão de preocupação moral, a sexualidade tornou-se um foco de produção de discursos pretensamente verdadeiros sobre o sujeito. Antes do século XIX as preocupações com o sexo eram preocupações referentes à religião ou à filosofia moral. Com o surgimento da sexologia, o sexo, ou melhor, a sexualidade (como passou a ser denominado no século XIX), tornou-se objeto de estudo científico, bem como configurou-se em uma preocupação generalizada de especialistas, da medicina, de profissionais e reformadores morais (Weeks, 1999).

É neste contexto histórico que surge o termo "homossexual", utilizado pela primeira vez na segunda metade do século XIX (Fry \& MacRae, 1985). Antes do esforço classificatório da sexologia, tais pessoas eram tidas como pertencentes a uma categoria geral e mal-definida denominada de sodomita, que se referia a todos aqueles que apresentavam um "potencial de natureza pecadora", e não a uma atividade própria de um tipo específico, delimitado, de pessoas (Weeks, 1999). Em outras palavras, como observou Foucault (1976/1997), o sodomita era considerado como uma "aberração temporária", enquanto o homossexual fazia parte de uma espécie própria, com características definidoras.

De "pecado", "crime", as relações afetivo-sexuais entre pessoas do mesmo sexo passam - com o surgimento histórico do conceito de homossexualidade - a ser consideradas "doença" e, por extensão, necessitam de tratamento e cura. Em outras palavras, buscou-se a delimitação "verdadeira" das identidades sexuais. Nesse sentido, procurou-se definir, por exemplo, os atributos (físicos, morais, dentre outros) que seriam "definidores da homossexualidade".

É interessante notar que as pessoas, guiadas pelo senso comum, acreditam existir uma divisão muito nítida e simples entre as identidades sexuais. Nesse sentido, haveria os "normais" (heterosssexuais) e os "anormais" (os homossexuais e os bissexuais) (Weeks, 1999). Mais do que isso, as identidades sexuais seriam o cerne das mais profundas verdades sobre o indivíduo. Através da explicitação da identidade sexual individual seria possível prever, um dos grandes ideais da ciência moderna, as suas qualidades morais, bem como se seria possível (ou não) a sua felicidade. Portanto não é de se estranhar a crença difundida na atualidade de que uma pessoa homossexual é imoral, promíscua e destinada à infelicidade. Sobre essa relação implícita entre infelicidade e homossexualidade, Foucault afirma que:

\footnotetext{
As pessoas dizem: "o prazer passa, a juventude acaba. Que eles tenham prazer, afinal sabemos que isso não os levará muito longe. Pagarão bem caro por esse prazer, com sofrimento e dor, com solidão, com rupturas, com disputas, com ódio ou com ciúme”, em suma, sabe-se que o prazer é compensado, e por conseguinte ele não incomoda. Mas a felicidade... A felicidade não é resgatada por nenhuma infelicidade fundamental... Então, as coisas se tornam intoleráveis. (Foucault citado por Eribon, 1994/1996, p. 168).
}

A delimitação das identidades sexuais faz parte, portanto, de um amplo processo histórico e cultural de normatização da sexualidade, ou seja, de institucionalização da heterossexu- 
alidade como a única forma "normal" de identidade sexual. Nesse processo, a definição do que constitui a anormalidade é essencial para se definir o que vem a ser a normalidade. Os dois esforços classificatórios estão, portanto, intrinsecamente relacionados (Louro, 1998, 1999, 2003; Weeks, 1999). Cabe enfatizar, também, que o processo de normatização da identidade heterossexual pressupõe um processo constante de estigmatização das identidades sexuais não-hegemônicas. Em outros termos, tais identidades passam a ser consideradas como identidades deterioradas que escondem uma "falha fundamental" (Goffman, 1963/1988).

Uma das premissas do modelo biomédico acerca da sexualidade é o estabelecimento de uma relação linear entre desejo sexual, comportamento sexual e identidade sexual. Contudo, essa relação linear tem sido questionada por diversos cientistas sociais (Parker, 1999; Weeks, 1999; Heilborn, 1996), o que parece indicar que a identidade sexual não pode ser simplesmente objetivada em um comportamento sexual específico. Esta diferenciação é particularmente importante na cultura sexual brasileira, na qual o "ativo" na relação sexual permanece no status de homem, enquanto o "passivo" torna-se "bicha". Nota-se, claramente, a importância da atividade e da passividade como referenciais significativos na construção das identidades sexuais na sociedade brasileira, principalmente entre os homens (Parker, 1991, 1994).

Nas análises sobre a construção das identidades sexuais é de fundamental importância considerarmos, também, as questões de gênero. Afinal não estamos nos referindo a sujeitos abstratos, mas a homens e mulheres inseridos em determinados contextos perpassados por significados culturais que delimitam as fronteiras simbólicas do que é socialmente esperado em relação às masculinidades e às feminilidades. Significados culturais que se articulam a sistemas de significação mais amplos que, por sua vez, trazem as marcas das estruturas desiguais de poder presentes nas relações entre homens e mulheres.

Os estudos de gênero constituem um campo de investigação interdisciplinar intrinsecamente vinculado ao movimento feminista, movimento social importante da segunda metade do século XX, voltado para a transformação das relações desiguais e hierárquicas entre homens e mulheres (Bandeira \& Siqueira, 1997). Assim, quando abordamos as questões de gênero não estamos nos referindo a mais um objeto de estudo, estamos nos referindo a um campo de investigação recente construído a partir do diálogo fecundo entre a produção acadêmica e a militância feminista. Como é evidenciado por Louro (1998), os estudos de gênero apresentam explicitamente pretensões de mudança. Em outras palavras, os estudos de gênero promovem a aliança entre o "fazer" científico e a militância política. Uma verdadeira heresia para os "guardiões" de uma ciência positivista ancorada no mito da neutralidade científica.

É importante esclarecer que o conceito de gênero é eminentemente relacional, ou seja, esta categoria analítica destaca o caráter relacional e político da constituição da(s) masculinidade(s) e feminilidade(s) (Fávero, 1997; Louro, 1998, 1999; Madureira \& Branco, 2004; Oliveira, 1998; Scott, 1995, 1998; Segato, 1997). Gênero consiste, portanto, em uma categoria analítica que viabiliza a compreensão de diversos fenômenos analisados pelas ciências humanas, além de apresentar uma dimensão claramente política.

Nesse sentido, é fundamental refletirmos sobre as relações de poder. Para tanto, as formulações foucaultinas são de grande valor heurístico. Mas o que seria o poder para Foucault? De acordo com Deleuze (1986/1988, p. 78, grifo nosso), "A definição de Foucault parece bem simples: o poder é uma relação de forças, ou melhor, toda relação de forças é uma 'relação de poder' (...)".

A visão do poder como algo essencialmente repressivo (que reprime os indivíduos, as pulsões, uma classe), é alvo de várias críticas de Foucault (1996, 1976/1997). Para ele, o poder não é apenas repressivo, este é apenas um lado da história. Afinal, a dominação capitalista não conseguiria se sustentar se fosse baseada unicamente na repressão (Foucault, 1996). As relações de poder devem ser consideradas não apenas como inibidoras, mas também como produtoras de condições de possibilidades para a constituição de determinados saberes, de individualidades (na forma de situar-se/relacionar-se com outras individualidades, como na percepção de si $)^{5}$.

Segundo Foucault (1996), o poder não deve continuar sendo considerado como "propriedade" do Estado, de uma classe social ou do homem, nas relações de gênero. Nem como mero "subproduto" das relações econômicas, apesar de manter conexões com as mesmas. Portanto, o poder não é uma entidade: “(...) os poderes não estão localizados em nenhum ponto específico da estrutura social. Funcionam como uma rede de dispositivos ou mecanismos a que nada ou ninguém escapa, a que não existe exterior possível, limites ou fronteiras (...)"(Machado, 1996, p. xvi ). O que existe é um constante e dinâmico confronto de forças, de opressões e resistências.

Neste artigo será privilegiada a conceituação de "identidades sexuais não-hegemônicas" ao invés do conceito, difundido na atualidade, de homossexualidade. Tal preferência conceitual foi inspirada na crítica do psicanalista brasileiro Jurandir Freire Costa (1992) ao conceito de homossexualidade. De acordo com este autor, a suposta "tranqüilidade" com que as pessoas são classificadas em homossexuais, bissexuais e heterossexuais esconde toda uma diversidade de práticas, sentimentos e auto-definições que tal classificação parece obscurecer (Costa, 1992). Essa classificação, intrinsecamente relacionada à medicina do século XIX, está vinculada ao ideal de delimitação "verdadeira" das identidades sexuais, a fim de predizer os atributos que caracterizariam todos(as) aqueles(as) que venham a ser "diagnosticadas" como homossexuais, como foi discutido anteriormente.

Pode-se observar, portanto, uma clara aliança entre saber e poder, na medida em que a produção de verdades sobre o sujeito, a partir do processo histórico de medicamentalização do corpo e da sexualidade, serviria de aval não apenas para separar os "normais" dos "anormais", mas também para excluir estes últimos. Em síntese, o conceito de homossexualidade apresenta, pelo menos, duas limitações: a) obscurece a diversidade de práticas, sentimentos e auto-definições entre

5 Sobre a hermenêutica do sujeito, última fase da obra de Foucault, consultar: A história da sexualidade II: o uso dos prazeres (1984/1994) e A história da sexualidade III: o cuidado de si (1984/1985). 
aqueles que recebem este rótulo; b) obscurece também a dimensão política que está em jogo na busca pela "essência verdadeira" (causalidade última) das orientações sexuais.

Nesse sentido, é importante utilizarmos um conceito que explicite as relações de poder que permeiam a "delimitação científica" das identidades sexuais. Para tanto, buscou-se no conceito de hegemonia essa possibilidade conceitual ${ }^{6}$. $\mathrm{O}$ conceito de hegemonia parece trazer à tona as relações de poder, os mecanismos de exclusão, os preconceitos e as práticas discriminatórias que estão no cerne do "processo pelo qual um determinado grupo social garante o domínio político da sociedade" (Silva, 2000, p. 65). Assim, o conceito de identidades sexuais não-hegemônicas se refere a: a) sujeitos que apresentam uma orientação homoerótica e que b) ocupam uma posição social marginal em relação à norma heterossexual nas sociedades ocidentais contemporâneas.

A conceituação de identidades sexuais não-hegemônicas traz para o centro das atenções a relação entre sujeito e cultura. Afinal, tal conceituação só faz sentido a partir da análise dos contextos culturais específicos e do espaço social conferido às orientações homoeróticas em tais contextos. Nesse sentido apresentaremos, nos próximos tópicos, a pesquisa qualitativa ${ }^{7}$ que realizamos sobre a construção das identidades sexuais não-hegemônicas na cidade de Brasília - DF. O que será apresentado, obviamente, é um recorte que focaliza alguns resultados importantes da pesquisa em questão.

\section{Método}

Participaram da pesquisa seis homens e quatro mulheres de classe média do Distrito Federal (faixa etária entre 20 e 34 anos), que se percebem como pessoas que apresentam uma orientação sexual distinta da heterossexualidade.

Foi realizada uma entrevista semi-estruturada com cada participante. No momento da realização das entrevistas foi entregue a cada participante uma carta de apresentação da pesquisa (com a descrição do tema e do objetivo da pesquisa). Se estivessem de acordo em participar, era, então, solicitado que assinassem o Termo de Consentimento Livre e Esclarecido. Foi explicitado na carta de apresentação da pesquisa, e enfatizado pela pesquisadora, que o nome de cada participante seria mantido em sigilo, ou seja, seriam substituídos por nomes fictícios. Foi esclarecido, também, que não eram esperadas "respostas certas" por parte dos(as) participantes, mas sim as suas opiniões e posicionamentos pessoais em relação às questões abordadas.

6 Segundo Tomaz Tadeu da Silva (2000, p. 65): "Hegemonia - Na teoria política mais geral, significa simplesmente 'predomínio político'. $\mathrm{Na}$ teoria educacional crítica é utilizado a partir da conceptualização desenvolvida pelo filósofo italiano Antonio Gramsci, o qual define hegemonia como o processo pelo qual um determinado grupo social garante o domínio político da sociedade. Para Gramsci, este domínio depende da construção de um consenso social, obtido através da construção de categorias culturais que acabam por se transformar em senso comum (...)".

7 Para uma análise das questões epistemológicas e metodológicas relativas à pesquisa qualitativa em Psicologia do Desenvolvimento, consultar Madureira e Branco (2001).
Foi elaborado, inicialmente, um sumário de todas as 10 entrevistas realizadas. Tal sumário consistiu na realização de comentários sintéticos e na transcrição de trechos considerados interessantes ou significativos das entrevistas. A partir da realização do sumário foi possível construir um panorama amplo sobre o grupo de participantes, bem como selecionar as entrevistas que seriam analisadas de forma mais aprofundada. As seis entrevistas selecionadas (três homens e três mulheres) foram, então, transcritas na íntegra. Buscouse, na transcrição das entrevistas, integrar às verbalizações os elementos paralingüísticos ${ }^{8}$ (como, por exemplo, a ênfase em certas palavras), visando o enriquecimento da análise e possibilitando uma maior compreensão da dimensão metacomunicativa (relacional) presente no momento da entrevista.

A análise das entrevistas buscou, nas narrativas dos(as) participantes, evidenciar os processos identitários relacionados às questões de gênero e às orientações sexuais, procurando articular os significados culturais e a constituição da subjetividade. As análises foram orientadas a partir das seguintes categorias temáticas: 1 ) história de vida; 2 ) questões de gênero; 3) movimentos sociais, discriminação e transformação da sociedade; 4) comunidade gay em Brasília; 5) gênese e desenvolvimento da orientação sexual; 6) crenças sobre a homossexualidade e classificação das orientações sexuais; 7) relações sociais (família, escola, trabalho, amizades); 8) relações afetivo-sexuais; 9) relações consigo mesmo(a); 10) outras questões e comentários sobre a entrevista.

Considerando que os participantes fazem parte de um grupo socialmente discriminado, o cuidado com o sigilo em relação às suas identidades foi redobrado na pesquisa. Além de adotarmos nomes fictícios para os participantes e todas as pessoas citadas nas entrevistas, omitimos informações que poderiam facilitar a identificação dos participantes (como, por exemplo, a especificação precisa da profissão). Dessa forma, pretendemos assegurar a integridade dos participantes e o respeito aos seus direitos enquanto sujeitos de pesquisa, dentre aqueles, o direito ao sigilo em relação à identificação pessoal.

\section{Resultados e Discussão}

O estudo indicou a relevância de se considerar as estratégias pessoais e coletivas utilizadas no cotidiano para lidar com o preconceito e a discriminação em relação às identidades sexuais que divergem da norma heterossexual. Tais estratégias são constitutivas da forma como os participantes vivenciam as suas experiências homoeróticas, suas relações sociais e consigo mesmos. Podemos afirmar, inclusive, que este é o denominador comum de todas as entrevistas realizadas. Mesmo quando os participantes não relatam situações concretas de discriminação, essa questão se faz presente em

8 Códigos utilizados na transcrição das entrevistas: $(. .$.$) = pausa longa$ na fala ... = pausa breve na fala ___ = ênfase na(s) palavra(s) sublinhada(s) [?] = uma palavra ininteligível [???] = mais de uma palavra ininteligível * = "hum, hum", "ham, ham", expressão que indica que a pesquisadora está acompanhando a fala do(a) participante (ou vice-versa) $($ risos $)=$ risos por parte da pesquisadora e do(a) participante ( risos -.....) = risos por parte da pesquisadora ou do(a) participante. 
termos prospectivos, ou seja, através do receio de se sentir discriminado em momentos futuros. Esse receio é verificado na atitude de evitar explicitar a própria orientação sexual (principalmente na família e no trabalho), a fim de não gerar situações constrangedoras.

O receio em explicitar a própria orientação sexual ${ }^{9}$, em um contexto sociocultural mais amplo atravessado pela homofobia, está associado à construção de uma rede intrincada de "ditos" e "não-ditos" que implica em um certo grau de ambigüidade nas relações sociais, requerendo um menor ou maior investimento pessoal em relação ao ocultamento da própria orientação sexual. Lidar, no cotidiano, com essa rede intrincada de "ditos" e "não-ditos" representa, em diferentes graus, um foco de ansiedade, de sofrimento psíquico, ainda mais se considerarmos o esforço contínuo que demanda ocultar a orientação sexual de pessoas com quem se tem forte vínculo afetivo (familiares, amigos/as).

A construção dessa rede é evidenciada, por exemplo, em relação à própria orientação sexual, por exemplo, na entrevista com Fabrício (25 anos; nome fictício). Nela, o participante adotou uma divisão clara entre o seu grupo de amigos: de um lado, os seus amigos heterossexuais; de outro lado, os seus amigos homossexuais:

"Sabe, entre aspas, né, entendeu*, eu já apresentei amigo... é... gay meu pra amigo hetero meu*, mas sem nenhum saber que um é e o outro é*, entendeu, cê apresenta aqueles que não dão muita pinta, como dizem, né*, que não chamam muita atenção*... [???] vou apresentar, por exemplo... um desses amigos meus que adora... é... tem festa a fantasia, é doido pra botar uma peruca, um sutiã e sair de sainha, né* (risos - Ana Flávia), então, ele dá, tem altos trejeitos e não sei o que, eu não vou apresentar um desses pro... pessoal hetero, porque, com certeza, vai dar falatório**, com certeza*. Então, dá divisão, já fiz festa em casa que eu chamei os dois*, sem o menor problema, nenhum* desconfiou do outro*, quer dizer, você dá um toque antes, né*: olha... geralmente pros gays, pros heteros não precisa avisar, ó... o pessoal que tá lá não sabe ${ }^{*}$, quero que continue assim, então*... beleza, não sei o que."

"Porque, pô, a gente sofre muito, né*, pra enfrentar esse tipo de relação*. É... e se você não tiver uma cabeça boa... pouquíssimos são os que agüentam*... levar... a vida assim tranqüila, tendo que conviver com gente que é, com gente que não é* ${ }^{*}$,tendo que dar suas mentirinhas aqui e ali, pra conseguir* fazer tudo co-existir direitinho*. Tem gente que odeia, eu conheço gente que, putz, quer sair, tem que dizer pro pai que tá indo sair com a fulaninha pra ir na boate e vai

9 De acordo com Pierre Bourdieu (1998/2005, p. 143-144, grifo nosso), "A forma particular de dominação simbólica de que são vítimas os homossexuais, marcados por um estigma que, à diferença da cor da pele ou da feminilidade, pode ser ocultado (ou exibido) (...) A opressão como forma de 'invisibilização' traduz uma recusa à existência legítima, pública, isto é conhecida e reconhecida, sobretudo pelo Direito, e por uma estigmatização que só aparece de forma realmente declarada quando o movimento reivindica a visibilidade. Alega-se, então, explicitamente, a 'discrição' ou a dissimulação que ele é ordinariamente obrigado a se impor." sair com o namorado... isso parte a pessoa em quinze, de mentir pro pai, pra mãe* e não sei o que."

Para o participante parece que não há outra opção: “é a questão de você ter que ter duas vidas". Nesta entrevista ficou evidente a existência daquela rede de "ditos" e "não-ditos", a qual demanda certos cuidados para sua manutenção. Cabe destacar, também, a utilização freqüente pelo participante da terceira pessoa do plural, "eles" ("as pessoas" ou "tem gente que...") para expressar o sofrimento vivido por muitos(as) que não são heterossexuais. Pela repetição freqüente desta temática, levantamos a hipótese que o participante realizou uma espécie de deslocamento (da primeira pessoa do singular, "eu", para a terceira pessoa do plural, "eles") para expressar o seu próprio sofrimento. Esta entrevista ilustra a complexa relação entre as estratégias utilizadas no cotidiano para lidar com o preconceito e a discriminação e a questão do sofrimento psíquico.

Em ambientes em que expressar a própria orientação sexual nas relações sociais é uma questão potencialmente problemática (em diferentes níveis), participar da "comunidade gay" - compreendida de forma genérica como os lugares de diversão e convivência voltados para o público homossexual e bissexual - adquire um papel importante. Cabe questionarmos: até que ponto a expansão de produtos e serviços voltados para o público gay em centros urbanos, como Brasília, representa um indício de transformação social?

Analisando a "comunidade gay" em Brasília, esta parece representar:

a) uma estratégia concreta, situada histórica e culturalmente, para que as pessoas que apresentam uma identidade sexual não-hegemônica se sintam protegidas do preconceito e da discriminação, que também permite a elas desenvolverem um sentimento de pertencimento a um grupo social de referência (processos identitários) e, desta forma, não se sentirem isoladas;

b) o fortalecimento de um setor do comércio voltado a uma clientela específica (gays e lésbicas de classe média/ alta), com um poder aquisitivo considerável (a maioria não tem que gastar, por exemplo, com a educação de crianças), o que torna este ramo de negócios bastante lucrativo;

c) uma estratégia que, analisada de perto, não colabora efetivamente na transformação social na medida em que mantém "cada um no seu lugar", ou seja, não coloca em xeque o preconceito e a discriminação em si, mantendo as fronteiras simbólicas que separam o "universo heterossexual" do "universo homossexual".

Reconhecemos a importância em termos identitários dos lugares de diversão e convivência voltados para aqueles(as) que apresentam uma identidade sexual não-hegemônica, em um universo marcado pela homofobia. Todavia, levantamos sérias dúvidas em relação a seu potencial transformador.

A diversidade de orientações sexuais é separada, dividida, circunscrita a determinados espaços físicos e sociais: aqui, os(as) heterossexuais (pelo menos explicitamente), ali, os(as) homossexuais. Assim, a diversidade é "administrada" de uma forma bastante eficaz no sentido de evitar possíveis conflitos. Mas será esta a melhor estratégia para construir uma cultura democrática, de valorização do outro e da diversidade? Os perigos da segregação estão em toda e qualquer categori- 
zação ou rótulo entre seres humanos. Ou seja, é necessário considerarmos seriamente a questão do preconceito e da discriminação, tanto na esfera da cultura, das relações sociais, como no plano subjetivo.

O preconceito é um fenômeno que apresenta suas raízes no universo simbólico da cultura, nas relações de poder que perpassam as diversas instâncias sociais, apresentando, portanto, uma dimensão coletiva. Por outro lado, considerando a gênese social do desenvolvimento individual - em consonância com a perspectiva sociocultural construtivista - 0 preconceito traz implicações no plano das interações sociais e no plano subjetivo, na forma como o sujeito vivencia, em termos cognitivos e afetivos, as suas experiências cotidianas, organiza a sua compreensão sobre si mesmo e sobre o mundo social em que está inserido.

A discriminação corresponde ao preconceito posto em ação. É, justamente, neste sentido que podemos afirmar que as práticas discriminatórias são sustentadas por idéias preconcebidas. Apesar da importância, em termos analíticos, da distinção entre preconceito e discriminação, ambos se encontram bastante vinculados no cotidiano. A relação entre preconceito e discriminação é bastante complexa, pois há uma integração entre as esferas da ação, da cognição e da emoção. Se a discriminação está vinculada à ação em relação a determinadas pessoas e grupos sociais, o preconceito não está ancorado apenas na cognição, mas está especialmente ancorado na emoção.

De forma mais específica, a homofobia, que sustenta e é sustentada por concepções preconceituosas e práticas discriminatórias em relação às pessoas que apresentam uma orientação distinta da heterossexualidade, apresenta tanto uma dimensão social como subjetiva (homofobia internalizada). Tanto homens como mulheres que apresentam uma identidade sexual não-hegemônica se constituíram enquanto sujeitos em contextos socioculturais marcados, em diferentes graus, pela homofobia, por uma concepção de normalidade que exclui outras possibilidades de vivência da própria sexualidade.

A homofobia internalizada, emocionalmente enraizada, no caso das pessoas que apresentam uma orientação homoerótica traz um potencial desestruturante em termos subjetivos, ou seja, consiste em um foco de sofrimento psíquico (culpa, ansiedade, depressão...). Em outras palavras, a violência simbólica ${ }^{10}$ subjacente à homofobia social (plano intersubjetivo) reaparece como violência contra si mesmo(a) (plano subjetivo). Além disso, pode implicar em uma dissociação entre os desejos, as fantasias e as relações afetivo-sexuais homoeróticas vivenciadas e outras dimensões importantes de si mesmo(a). Tal dissociação pode ser ilustrada na entrevista com Renata (25 anos, nome fictício). Sobre a possibilidade de a participante contribuir, pessoalmente, na luta contra o preconceito e a discriminação por orientação sexual, ela afirma que:

10 Para uma análise aprofundada sobre a violência simbólica nas relações de gênero e nas relações entre heterossexuais, gays e lésbicas, consultar: Bourdieu (1998/2005).
“Eu tento mostrar pra esse lado*, que eu acabei de falar*, é... pras pessoas que me conhecem que sabe... que... tudo bem, que não são muitas que sabem que eu, que eu seja, entendeu?* Mas eu, eu tento mostrar esse lado... é... eu sou, mas... eu tento mostrar pra elas que eu sou isso... dentro de quatro paredes, ninguém tem nada a ver com isso*, tem eu e a pessoa com quem eu tô ${ }^{* *}$... o restante disso, eu tô fazendo um... eu sou uma pessoa normal $^{* *}$, entendeu. Então, acho que é, que é por aí, através do respeito que você tem com a outra pessoa que você vai dando a seguri... a, a ... dando... é... segurança pra pessoa* ver que aquilo ali não é nenhum bicho de sete cabeças**... por aí.”

É interessante notar a dissociação que a participante realiza entre a sua orientação sexual e as outras dimensões de sua vida, como se a sua orientação sexual fosse completamente circunscrita a "quatro paredes". Na realidade, a participante parece "afastar dos olhos" de outras pessoas as suas experiências homoeróticas, a fim de se apresentar como uma "pessoa normal". Essa estratégia torna-se evidente quando diz (com ênfase): “eu sou, mas...”. Tal expressão traz em si a idéia de solicitação de desculpas pelo que se é, ou, em outras palavras, "sou homossexual, mas tenho uma vida normal".

Em última instância, ela percebe a homossexualidade como algo "anormal", e busca "driblar" o preconceito e a discriminação tratando de encontrar para si uma função sublime: levar as "almas perdidas" do universo gay para a igreja católica. Os valores católicos e familiares tradicionais de Renata atuam para que ela se esforce em manter uma pretensa "harmonia social", criticando o movimento gay para evitar conflitos entre as pessoas. Tende a enfatizar a continuidade (e não a transformação) de valores e crenças. Nesse sentido, parece que as alternativas mais adequadas para alguém em sua situação seriam: a) não explicitar a sua orientação sexual; b) quando explicitar, fazer com que esta seja percebida pelos outros como uma dimensão relativamente dissociada de si (algo circunscrito a "quatro paredes").

Impressiona, no caso de Renata, o quanto a homofobia internalizada pode conduzir a uma dissociação entre as vivências afetivo-sexuais e outras dimensões importantes de si mesmo(a), no que se refere a pessoas que apresentam uma orientação homoerótica.

Uma questão que suscitou posicionamentos divergentes nas entrevistas diz respeito à problemática da "promiscuidade". As três mulheres apresentaram maior homogeneidade de opinião sobre o tema, enquanto houve, entre os homens, uma maior diversidade. Parece, assim, que a percepção do que vem a ser "promiscuidade" é perpassada por questões de gênero. Primeiramente cabe destacar que a associação bastante freqüiente no imaginário social entre homossexualidade e "promiscuidade" parece estar vinculada à concepção tradicional de que a sexualidade, fora dos limites do casamento, seria uma sexualidade "desregrada, sem controle" e, portanto, "promíscua".

A construção da feminilidade e da masculinidade ocorre não apenas nas relações entre homens e mulheres, mas também intra-gênero, a partir do confronto com os contraideais de masculinidade e feminilidade (Parker, 1991). O contra-ideal de feminilidade é a promiscuidade, ou seja, tudo o que uma mulher não pode ser é "promíscua" (em termos populares, ser considerada "galinha"). Portanto, não é de 
se estranhar o movimento deliberado das participantes em afastar o rótulo de "promiscuidade" de si mesmas e do grupo social a que pertencem (mulheres com uma orientação homoerótica), deslocando este rótulo para os homens que apresentam uma orientação homoerótica: "são eles que são promíscuos, nós não somos”. Nas entrevistas com os homens, por outro lado, não houve o mesmo incômodo unânime com a questão da "promiscuidade", ou seja, as opiniões foram mais diversificadas a esse respeito.

Outra questão que gerou divergências nas entrevistas com homens e com mulheres diz respeito à forma como as relações afetivo-sexuais entre homens e entre mulheres são percebidas. Novamente, observou-se uma maior homogeneidade entre os posicionamentos no grupo de mulheres. Para elas, as relações afetivo-sexuais entre mulheres são percebidas a partir de um prisma que tende a enfatizar o vínculo afetivo e/ou a identificação intra-gênero, ou seja, a concepção de que as mulheres são "mais parecidas entre si”. Entre os homens, houve uma maior heterogeneidade de posicionamentos. Em nenhuma das entrevistas com homens o vínculo afetivo e/ou a identificação intra-gênero foram indicados como características definidoras das relações afetivo-sexuais entre homens, como ocorreu entre as mulheres.

Essas diferenças de posicionamentos indicam o quanto uma categoria ampla, homossexuais, não é homogênea, não apenas por ser formada por sujeitos singulares com uma história de vida particular mas também por ser perpassada por outras questões (como, por exemplo, questões de gênero, etnia, classe). Apesar de existirem pessoas que acreditam que os(as) homossexuais formam um grupo de pessoas que vivem em um mundo à parte, os(as) mesmos(as) são, na realidade, socializados e se constituem enquanto sujeitos em um mesmo contexto sociocultural amplo. Assim, as pessoas com identidades sexuais não-hegemônicas não estão "imunes" às canalizações culturais marcadas pelas questões de gênero. Nas relações afetivo-sexuais entre homens, a expectativa de atitudes associadas à virilidade e a capacidade de dissociação entre sexualidade e afetividade se fazem presentes.

De forma similar, no processo de socialização das mulheres existe a expectativa social de que a atividade sexual seja um canal para afetos que devem perdurar para além do ato em si (Heilborn, 1999). Em outras palavras, existe a expectativa social de valorização do vínculo afetivo e da cumplicidade nas relações afetivo-sexuais por parte das mulheres (tanto nas relações heterossexuais quanto nas relações homoeróticas).

No processo de se tornarem homens e mulheres, as pessoas com uma orientação homoerótica também deverão lidar com a multiplicidade de significados culturais, muitas vezes antagônicos, sobre os limites legitimados socialmente do que vem a ser a masculinidade e a feminilidade. Em um sentido amplo, as questões de gênero cumprem um papel estruturante na forma como as pessoas lidam com seus afetos, consigo mesmas, como se posicionam em suas relações afetivo-sexuais e nas suas relações sociais.

Os resultados da pesquisa indicam a importância da articulação, no estudo das identidades sexuais não-hegemônicas, entre as questões de gênero, as questões relacionadas às orientações sexuais e a constituição da subjetividade em contextos socioculturais complexos. Com isso será possível construir uma compreensão mais ampla e contextualizada, tanto sobre as identidades sexuais, como sobre as identidades de gênero. Compreensão útil, inclusive, na luta política travada tanto pela militância feminista, como pela militância GLTB (Gays, Lésbicas, Transgêneros e Bissexuais).

\section{Considerações Finais}

No presente artigo analisamos algumas questões referentes à construção das identidades sexuais não-hegemônicas, a partir da perspectiva sociocultural construtivista. Infelizmente, os espaços de diálogo entre a Psicologia e as Ciências Sociais ainda são muito limitados. Vários fatores contribuem para a manutenção desse distanciamento, como, por exemplo, a dificuldade (resistência?) em conceber a Psicologia como ciência humana, social, e não como ciência biológica. Outro fator para o distanciamento entre a Psicologia e as Ciências Sociais consiste no "olhar individualista" que tradicionalmente atravessou a Psicologia. É fundamental, pois, superarmos o "olhar individualista" e realizar pesquisas sobre as questões de gênero e sexualidade, no contexto de um diálogo interdisciplinar, para que se evitem concepções reducionistas e politicamente ingênuas, ancoradas no "porto seguro" do discurso biomédico tradicional.

Por último, gostaríamos de mencionar a Resolução $N^{o} 1 / 99$ do Conselho Federal de Psicologia (CFP) de 23 de março de $1999^{11}$, que estabelece normas de atuação para os(as) psicólogos(as) em relação à questão da orientação sexual. Em consonância com esta Resolução do CFP, a Psicologia deve colaborar na superação de concepções preconceituosas e de práticas discriminatórias em relação às identidades sexuais não-hegemônicas.

A realização de novas pesquisas sobre esta temática é, portanto, de suma importância. Tais pesquisas devem subsidiar a atuação de profissionais diversos e dos(as) psicólogos(as) nos distintos campos de intervenção profissional (nas escolas, nos consultórios, nas comunidades, nas organizações...). Afinal, os conhecimentos produzidos pela Psicologia podem - e devem - colaborar na transformação social, na construção de uma cultura democrática de valorização da diversidade em todos os níveis.

\section{Referências}

Bandeira, L. \& Siqueira, D. (1997). A perspectiva feminista no pensamento moderno e contemporâneo. Sociedade e Estado, 12(2), 263-284.

Bourdieu, P. (2005). A dominação masculina. (M.H. Kühner, Trad.) Rio de Janeiro: Bertrand Brasil. (Trabalho original publicado em 1998)

11 Parágrafo único - Os psicólogos não colaborarão com eventos e serviços que proponham tratamento e cura das homossexualidades. 
Bruner, J. (1997). Atos de significação. (S. Costa, Trad.). Porto Alegre: Artes Médicas. (Trabalho original publicado em 1990)

Cole, M. (1992). Culture in development. Em M. Bornstein \& M. Lamb (Orgs.), Developmental psychology: An advanced textbook (pp. 731-787). New Jersey: Erlbaum.

Costa, J.F. (1992). Os amores que não se deixam dizer. SaúdeLoucura, 3, 21-37.

Deleuze, G. (1988). Foucault. (C. S. Martins, Trad.) São Paulo: Brasiliense. (Trabalho original publicado em 1986)

Eribon, D. (1996). Michel Foucault e seus contemporâneos. (L. Magalhães, Trad.) Rio de Janeiro: Jorge Zahar. (Trabalho original publicado em 1994)

Fávero, M. H. (1997). Menina, moça e mulher: o ser feminino na psicologia. Em M. G. Gimenes \& Fávero, M. H. (Orgs.), A mulher e o câncer (pp. 23-42). Campinas: Editorial Psi.

Foucault, M. (1985). História da sexualidade 3: o cuidado de si. (M.T.C. Albuquerque, Trad.) Rio de Janeiro: Graal. (Trabalho original publicado em 1984)

Foucault, M. (1994). História da sexualidade 2: o uso dos prazeres. (M.T.C. Albuquerque, Trad.) Rio de Janeiro: Graal. (Trabalho original publicado em 1984)

Foucault, M. (1996). Microfísica do poder. (Edição com base em textos de Michel Foucault, organizada por R. Machado, Trad.) Rio de Janeiro: Graal.

Foucault, M. (1997). História da sexualidade 1: a vontade de saber. (M. T. C. Albuquerque \& J. A. G. Albuquerque, Trads.) Rio de Janeiro: Graal. (Trabalho original publicado em 1976)

Fry, P. \& MacRae, E. (1985). O que é homossexualidade. São Paulo: Abril Cultural/Brasiliense.

Goffman, E. (1988). Estigma: notas sobre a manipulação da identidade deteriorada. (M. B. M. L. Nunes, Trad.) Rio de Janeiro: Guanabara. (Trabalho original publicado em 1963)

González Rey, F. G. (1997). Epistemologia cualitativa y subjetividad. São Paulo: EDUC.

Hall, S. (1998). A identidade cultural na pós-modernidade. (T. T. Silva \& G. L. Louro, Trads.) Rio de Janeiro: DP\&A. (Trabalho original publicado em 1992)

Heilborn, M. L. (1996). Ser ou estar homossexual: dilemas de construção de identidade social. Em R. Parker \& R. M. Barbosa (Orgs.), Sexualidades brasileiras (pp. 136-145). Rio de Janeiro: Relume Dumará.

Heilborn, M. L. (1999). Construção de si, gênero e sexualidade. Em M. L. Heilborn (Org.), Sexualidade: o olhar das ciências sociais (pp. 40-58). Rio de Janeiro: Jorge Zahar.

Louro, G. L. (1998). Gênero, sexualidade e educação: uma perspectiva pós-estruturalista. Petrópolis: Vozes.

Louro, G. L. (1999). Pedagogias da sexualidade. Em G.L. Louro (Org.), O corpo educado: pedagogias da sexualidade (pp. 7-34). Belo Horizonte: Autêntica.

Louro, G. L. (2003). Currículo, gênero e sexualidade: o "normal", o "diferente" e o "excêntrico". Em G.L. Louro \& J.F. Neckel \& S.V. Goellner (Orgs.), Corpo, gênero e sexualidade: um debate contemporâneo na educação (pp. 41-52). Petrópolis: Vozes.

Machado, R. (1996). Introdução: por uma genealogia do poder. Em M. Foucault, Microfísica do poder (pp. VII-XXIII). Rio de Janeiro: Graal. (Edição com base em textos de Michel Foucault, organizada por Roberto Machado)
Madureira, A. F. A. \& Branco, A. U. (2001). A pesquisa qualitativa em psicologia do desenvolvimento: questões epistemológicas e implicações metodológicas. Temas em Psicologia da SBP, 9(1), 63-75.

Madureira, A. F. A. \& Branco, A. U. (2004). Coconstruction of gender identity in social interactions: The role of communication and metacommunication processes. Em A. U. Branco \& J. Valsiner (Orgs.), Communication and metacommunication in human development (pp. 151-189). Connecticut: Information Age Publishing.

Madureira, A. F. A. \& Branco, A.U. (2005a). Construindo com o outro: uma perspectiva sociocultural construtivista do desenvolvimento humano. Em M. A. Dessen \& A. L. Costa Júnior (Orgs.), A ciência do desenvolvimento humano: tendências atuais e perspectivas futuras (pp. 90-109). Porto Alegre: Artes Médicas.

Madureira, A. F. A. \& Branco, A. U. (2005b). A noção de sujeito na ciência psicológica: linguagem e constituição da subjetividade em discussão. Em F. G. Rey, (Org.), Subjetividade, complexidade e pesquisa em psicologia (pp. 127-153). São Paulo: Pioneira Thomson Learning.

Oliveira, M. K. (1993). Vygotsky: aprendizado e desenvolvimento - um processo sócio-histórico. São Paulo: Scipione.

Oliveira, P. P. (1998). Discursos sobre a masculinidade. Estudos Feministas, 6(1), 91-111.

Parker, R. (1991). Corpos, prazeres e paixões: a cultura sexual no Brasil contemporâneo. São Paulo: Editora Best Seller.

Parker, R. (1994). Sexo entre homens: consciência da AIDS e comportamento sexual entre homens homossexuais e bissexuais no Brasil. Em R. Parker, C. Bastos, J. Galvão \& J. S. Pedrosa (Orgs.), A AIDS no Brasil (pp.129-159). Rio de Janeiro: Relume Dumará.

Parker, R. \& Barbosa, R. M. (1996). Introdução. Em R. Parker \& R. M. Barbosa (Orgs.), Sexualidades brasileiras (pp. 7-13). Rio de Janeiro: Relume Dumará.

Parker, R. (1999). Cultura, economia política e construção social da sexualidade. Em G. L. Louro (Org.), O corpo educado: pedagogias da sexualidade (pp. 125-150). Belo Horizonte: Autêntica.

Rogoff, B. (2003). The cultural nature of human development. New York: University Press.

Scott, J. W. (1995). Gênero: uma categoria útil de análise histórica. Educação \& Realidade, 20(2), 71-99.

Scott, J. W. (1998). Ponto de vista: entrevista com Joan Wallach Scott. Estudos Feministas, 6(1), 114-124.

Segato, R. L. (1997). Os percursos do gênero na antropologia e para além dela. Sociedade e Estado, 12(2), 235-262.

Silva, T. T. (2000). Teoria cultural e educação: um vocabulário crítico. Belo Horizonte: Autêntica.

Valsiner, J. (1989). Human development and culture: the social nature of personality and its study. Lexington: Lexington Books.

Valsiner, J. (1994). Bidirectional cultural transmission and constructive sociogenesis. Em W. Graaf \& R. Maier (Orgs.), Sociogenesis reexamined (pp.47-70). New York: Springer.

Valsiner, J. (1997). Culture and the development of children's action. New York: Wiley.

Valsiner, J. (1998). The guided mind: A sociogenetic approach to personality. Cambridge: Harvard University Press. 
Vygotsky, L. S. (1991). A formação social da mente: odesenvolvimento dos processos psicológicos superiores. (J. C. Neto, L. S. M. Barreto \& S. C. Afeche, Trads.) São Paulo: Martins Fontes. (Trabalho original publicado em 1978)

Vygotsky, L. S. (1993). Pensamento e linguagem. (J. L. Camargo, Trad.) São Paulo: Martins Fontes. (Trabalho original publicado em 1962)
Weeks, J. (1999). O corpo e a sexualidade. Em G. L. Louro (Org.), O corpo educado: pedagogias da sexualidade (pp. 35-82). Belo Horizonte: Autêntica.

Recebido em 06.03.2006

Primeira decisão editorial em 13.06.2006

Versão final em 30.06.2006

Aceito em 15.08.2006 